\title{
Problems Encountered by College Students in Online Assessment amid COVID-19 Crisis: A Case Study
}

\author{
Michael B. Cahapay \\ College of Education, Mindanao State University, General Santos City, Philippines \\ mbcahapay@up.edu.ph
}

\begin{abstract}
The implementation of online assessment within the context of emergency remote learning presents a major practical concern for many students today. This paper aimed to describe the problems encountered by the students in online assessment amid the coronavirus disease 2019 (COVID-19) crisis. Following the case study as a research design, it involved students in a higher education institution in General Santos City, Mindanao, Philippines. Drawing from multiple data sources such as documents observations, and interviews, the researcher initially presented the case description. The results revealed six themes of problems encountered by the students in the online assessment. These problems are 1.) incompatibility of browser; 2.) anxiety over tracking tools; 3.) unstable internet connection; 4.) electric power interruptions; 5.) distractions in the environment; and 6.) unknown accessibility issues. This paper draws several useful recommendations. It is suggested that, in selecting the application to use for online assessment, school administrators should consider the complexity of the application but without compromising its capacity to guard assessment integrity. Moreover, given the knowledge about the selected application, teachers should prepare alternative measures should inevitable problems like the ones found in this study occur. Lastly, to keep the students guided throughout the online assessment, it is proposed that courses should include a test orientation and provide a test manual for the students.
\end{abstract}

Keywords: Problems, Online assessment, New normal, COVID-19 crisis, Case study

\section{Introduction}

As COVID-19 ravaged the world, educational institutions were forced to shut down and then slowly reopened in the attempt to continue education despite the situation. Most educational institutions in almost all countries have turned to emergency remote education, a temporary alternative of instructional delivery that provides students with necessary instructional support [1] and a 'responsibility' rather than a 'choice' in this time of crisis. On the other hand, this phenomenon has created exceptional challenges when it comes to how instructional components may be translated into the remote learning modality. Thus, educators are placed in a sort of experimental quandary, testing which option works given the situation.

The Global Education Monitoring Report [2] has raised educational issues, of which one concerns the assessment component of instruction and student learning. It was observed that as the COVID-19 crisis extended from the acute phase, educators also pivoted from stressing continuous instruction and technology access to one important outcome: grades. As a response

Article history:

Received (January 9, 2021), Review Result (February 8, 2021), Accepted (March 17, 2021) 
to such an extraordinary global phenomenon, many educators were quick to caution "do no harm" methods of assessment [3]. This phenomenon is a part of the new assessment practices such as using previous grades from mock exams, applying observational assessments of teachers, and considering prior grade expectations [4].

Within the Philippine context, the Commission on Higher Education (CHED) is the national body that regulates policies for higher education institutions. Responding to the impacts of the COVID-19 crisis on education which coincided with the end of the school year, it issued the COVID Advisory No. 6 series of 2020 articulating guidelines on how assessment can be redesigned in the acute phase. For one, it authorized the colleges and universities all over the country to undertake alternative assessments and remediations and consider student assessment and calculation of grades to be based on current student records and school academic policies [5]. Such guidelines were adapted or modified by the colleges and universities, with consideration of their different contextual conditions on the ground.

Within the context of the higher education institution under this study, the student situation is fraught with various difficulties in remote learning [6] including the assessment process. It was reported that students encounter unstable internet connectivity, inadequate learning resources, and electric power interruptions as major hurdles to learning. They also expressed problems like vague learning contents, overloaded lesson activities, limited teacher scaffolds, poor peer communication, conflict with home responsibilities, and poor learning environment. These barriers have taken a toll on their financial, physical, and mental aspects [6].

Compounding the situation is the contamination of assessment of learning called "test pollution" [7] which has presented negative impacts as confinement [8] and other serious issues continue to affect students amid forced migration to remote education. Thus, measures are needed to put both an equitable and valid assessment in place. These measures may be formulated based on contextual experiences on the problems that beset students in the field. A few scholarly works set in different countries have tackled this area of interest [9][10][11]. with the practical purpose to enhance assessment of student learning in the end. However, no studies have been written to capture problems in online assessment at the present moment of emergency remote learning. The current paper will contribute to this area of interest through a description of problems encountered by students in an online assessment set in a country with a unique structural context and amid the global COVID-19 crisis.

Thus, this case study aims to describe the problems encountered by the college students in online assessment amid the COVID-19 crisis. With this research aim, the description of the problems experienced by students in an online assessment in the current context of the study will be significant. It will serve as practical insight for the continuous improvement of assessment practices amid the difficult situation and generate theoretical knowledge in this area of interest.

\section{Methods}

\subsection{Research design}

This paper used a case study as a research design. A case study investigates a real and contemporary single bounded system or multiple bounded systems in a particular period. Moreover, it gathers evidence through detailed data collection involving multiple sources of information [12]. It is an appropriate research design for this paper as it provided a more focused approach and descriptive method in investigating the problems faced by the college students in the online assessment amid the COVID-19 crisis. 


\subsection{Case participants}

This research involved a total of 153 students enrolled in an undergraduate program in a higher education institution during the school year 2020-2021. As research participants, they were selected through purposive sampling. This sampling technique is suited in this study because the main criterion was followed in selecting the participants. This study specifically selected students with direct experience in the online assessment. These participants were further selected regardless of their age, sex, religion, course standing, socioeconomic status, and geographical location.

\subsection{Case background}

This case study was conducted in a higher education institution in General Santos City, Philippines. On March 13, 2020, amid the COVID-19 acute phase, the Commission on Higher Education or CHED issued Advisory No. 6 which urged tertiary institutions to arrange flexible learning and other alternative modalities of instruction to offset traditional campus learning. It suggested that schools employ responsive approaches to student assessment. Some of these responsive approaches include changes in the grading component focusing on student attendance; the grading system shifting to descriptive binary, and requirements for laboratory and research works significantly modified [5].

\subsection{Data sources}

The data for this research were primarily derived from documents, observations, and interviews as prescribed for case studies. The documents used were in the form of preserved soft copies such as memorandum order, course syllabus, and test manual that were part of the learning package provided to the students. On the other hand, the researcher also considered observations in the process of building a continuous record of transactions occurring in the group. Since most interactions happen online, textual communications in the learning management system served as observation units. Furthermore, a series of structured online interviews were conducted as a source of validation of the results.

\subsection{Data analysis}

The information obtained from multiple sources was subjected to thematic analysis, a technique "for identifying, analyzing and reporting patterns within data." [13]. This technique is suited in the process of identifying significant codes which served as a basis for categorizing the data triangulated from the documents, observations, and interviews. The related significant codes were then combined and cataloged into themes. Furthermore, the results of the analysis were presented following a proposed structure [14] in writing case studies. It is advised that in specifically writing the results of case studies, there are two main sections. These sections are the case description and case themes.

\section{Results}

\subsection{Case description}

Through Advisory No. 3 dated March 11, 2020, the Philippine CHED issued guidelines that have implications to the assessment practices in higher education institutions. It directed institutions to facilitate alternative activities to enable students to complete the required 
practicum and evaluate students based on available assessment evidence. This was followed by Advisory No. 6 dated March 13, 2020, urging tertiary institutions anew to consider ways how to meet the requirements for the completion of a course or degree [5].

These advisories had authorized higher education institutions to exercise liberty on how student assessment may be conducted amid the emergency period. The case setting under this study is one of these higher education institutions. As a result, changes were adapted within the temporal, logistical, and cultural contexts of the institution. These changes were evident in the grading components, grading system, laboratory work completion, research work completion, and grade computation [4].

As the higher education institution reopened a few months ago, one of the challenges that students have to cope with is the structural requirements for the implementation of remote instruction which includes the assessment component. The students have to cope with such challenges in terms of internet connection, electricity access, and learning resources such as gadgets to use. As a result, they needed to employ various strategies and measures to cope with the situation fraught with such obstacles [15].

Table 1. Thematic analysis of problems in online assessment

\begin{tabular}{|c|c|}
\hline Significant codes & Theme \\
\hline $\begin{array}{l}\text { I have a little problem with my browser but which I was able to solve now. } \\
\text { I am using Google Chrome. I just needed to update with a newer browser } \\
\text { version to work. }\end{array}$ & \multirow[t]{2}{*}{ Incompatibility of browser } \\
\hline $\begin{array}{c}\text { I still cannot open the online demonstration test even if I have updated my } \\
\text { Google Chrome browser with a new version. I downloaded and tried the } \\
\text { Mozilla Firefox browser and it worked. }\end{array}$ & \\
\hline $\begin{array}{l}\text { The tracking tool displayed messages that there were multiple faces } \\
\text { detected though I am alone. I worried that it may affect the result of my } \\
\text { trust report. }\end{array}$ & \multirow[t]{2}{*}{ Anxiety over tracking tools } \\
\hline $\begin{array}{c}\text { I used to verbally read the question to myself especially if I cannot } \\
\text { understand it. However, I have to control myself this time because my } \\
\text { voice may be tracked as a noise. }\end{array}$ & \\
\hline $\begin{array}{l}\text { I am finished with the test but the submit button does not function because } \\
\text { my internet connection was suddenly lost. Can I screen grab my test } \\
\text { instead and submit? }\end{array}$ & \multirow[t]{2}{*}{ Unstable internet connection } \\
\hline $\begin{array}{l}\text { We do not have a good internet connection at home. I have to travel to } \\
\text { another village just to find a strong internet connection and so I can take } \\
\text { the test. }\end{array}$ & \\
\hline $\begin{array}{l}\text { We were hit by a magnitude six earthquake this early morning. We are } \\
\text { badly affected and we do not have electricity within our town right now. }\end{array}$ & \multirow[t]{2}{*}{ Electric power interruption } \\
\hline $\begin{array}{c}\text { I do not have a power bank. We suddenly lost electricity as early as 5:00 in } \\
\text { the morning. My phone battery was drained even before the start of the } \\
\text { test. }\end{array}$ & \\
\hline $\begin{array}{l}\text { It suddenly poured while I was taking the test. I am disturbed that the } \\
\text { patter of the raindrops on our galvanized roof can be detected by the } \\
\text { tracking tool. }\end{array}$ & \multirow[t]{2}{*}{$\begin{array}{l}\text { Distractions in the } \\
\text { environment }\end{array}$} \\
\hline $\begin{array}{l}\text { My mom already asked our neighbor to lower down the volume of their } \\
\text { karaoke because I am taking the test, but I still can hear it I cannot } \\
\text { concentrate on the test. }\end{array}$ & \\
\hline $\begin{array}{l}\text { I check my device and browser with the online demonstration test every } \\
\text { day. I do not know why the same device and browser cannot access the test } \\
\text { now. }\end{array}$ & \multirow[t]{2}{*}{ Unknown accessibility issues } \\
\hline $\begin{array}{l}\text { I was able to access the online test but all it shows is a blank screen. I can } \\
\text { see the tracking tool and the timer is running, but the test questions are not } \\
\text { displayed. }\end{array}$ & \\
\hline
\end{tabular}


Considering the situation, teachers should design an assessment that considers the structural limitations but still maintains the integrity of the assessment [16]. The course under study employed an assessment through a virtually proctored test application that uses artificial intelligence. It uses tracking sources such as a camera and microphone. It detects multiple faces, captures when the student disappears, records suspicious noises, and tracks if a file is opened. It gives the teacher, in the end, a "trust" report which may be reviewed and made basis whether to accept the test outcome of a particular student or not.

The test is a cognitive test composed of a hundred items and framed in the format of multiplechoice intended to measure the level of acquisition of skills of the students. The duration of the test is approximately 80 minutes which is based on the standards [17] that for objective tests at the college level conducted online, approximately 45 seconds per question is adequate. As a preparation for the online assessment, the course adviser created a student test manual to guide the students throughout the test period.

\subsection{Case themes}

Five themes on the problems encountered by the students in the online assessment emerged from the analysis of the data from various sources. They are presented in Table 1 and discussed as follows.

\subsubsection{Theme 1: Incompatibility of browser}

The online test application requires a certain browser for a type of device to functionally work. The problem of incompatible browsers was encountered days before the test as the students were instructed to test their devices and browsers ahead through the available online test demonstration.

Many students had a minor problem as they use an old version of a browser for their remote learning and they have to update it. One expressed that: "I have a little problem with my browser but which I was able to solve now. I am using Google Chrome. I just needed to update with a newer browser version to work" (Student 09).

Other students have a problem as they cannot access the online test using their updated version of the browser. They have to download a new one. A student posted: "I still cannot open the online demonstration test even if I have updated my Google Chrome browser with a new version. I downloaded and tried the Mozilla Firefox browser and it worked" (Student 55).

\subsubsection{Theme 2: Anxiety over tracking tools}

Moreover, students felt anxious over live reports of the tracking tools of the online test application while they were taking the test. It should be noted that the application uses the camera and microphone accessories of the device to track anomalies that may present a potential incidence of test dishonesty.

One student recalled that he was anxious because the online test application tracking tool kept reporting that multiple faces were detected when he was alone in his room taking the test: "The tracking tool displayed messages that there were multiple faces detected though I am alone. I worried that it may affect the result of my trust report" (Student 76).

Another student stated that because the human voice is considered noise, she cannot read the question aloud to herself, a learning style that she employs to better understand the test: "I used to verbally read the question to myself especially if I cannot understand it. However, I have to control myself this time because my voice may be tracked as a noise" (Student 12). 


\subsubsection{Theme 3: Unstable internet connection}

The problem related to poor internet signal is a major issue in the remote learning of the students. However, it may be more serious in an assessment that is restricted by time and needs to be submitted on time.

A student reported while taking the test that, due to an unstable internet connection, she is not able to click the submit button at the end. She recounted: "I am finished with the test but the submit button does not function because my internet connection was suddenly lost. Can I screen grab my test instead and submit?" (Participant 98).

Some students are located in remote areas. One of them spoke that she has no stable internet connection and has to travel somewhere to find a stable one: "We do not have a good internet connection at home. I have to travel to another village just to find a strong internet connection and so I can take the test" (Participant 148).

\subsubsection{Theme 4: Electric power interruption}

At least a quarter of the students took the test on a delayed schedule because of the unscheduled power interruption in their respective areas. While their device battery may sustain the entire duration of the test, the internet signal depends on the electricity. Thus, because of the electric power interruption, they were not able to take the test on time.

Unexpected events caused electric power interruptions. As a result, some students located in particular areas were not able to take the online test. One of them immediately informed that: "We were hit by a magnitude six earthquake this early morning. We are badly affected and we do not have electricity within our town right now" (Student 102).

There was a student who had no electricity for the whole day. This is exacerbated by a device battery with a low capacity to store power and no power bank. She narrated that:

"I do not have a power bank. We suddenly lost electricity as early as 5:00 in the morning. My phone battery was drained even before the start of the test." (Student 139).

\subsubsection{Theme 5: Distractions in the environment}

Although the students have the time before the test to prepare a test spot with the least disruptions, some distractions in the environment are inevitable. This problem affected their concentration and added also to their anxiety over tracking tools reporting detected noises.

One student informed the course adviser that she worried it was noisy because there was heavy rain in their area on the day of the test: "It suddenly poured while I was taking the test. I am disturbed that the patter of the raindrops on our galvanized roof can be detected by the tracking tool" (Student 107).

Another student also reported that she was not able to completely focus on the test because of the noise coming from their neighbor: "My mom already asked our neighbor to lower down the volume of their karaoke because I am taking the test, but I still can hear it I cannot concentrate on the test" (Student 63).

\subsubsection{Theme 6: Unknown accessibility issues}

There were at least five students who were not able to take the test on time because of unknown accessibility issues. They were able to previously access the online test demonstration, but due to unknown reasons, they were not able to completely access the main test on the day using the same device and browser. 
One of these students explained that, for an unknown reason, she suddenly cannot access the test application which she used to accessed days prior: "I check my device and browser with the online demonstration test every day. I do not know why the same device and browser cannot access the test now" (Participant 24).

A few students reported also that they were able to access the test but there was nothing on the screen. Someone shared that: "I was able to access the online test but all it shows is a blank screen. I can see the tracking tool and the timer is running, but the test questions are not displayed" (Participant 111).

\section{Discussion}

The implementation of online assessment is a practical concern in the context of emergency remote learning and there is a scarcity of theoretical knowledge arising from the current context. Given these needs, this paper aimed to describe the problems encountered by college students in online assessment amid the COVID-19 crisis. Six themes of problems in the online assessment were uncovered in this study: incompatibility of browser; anxiety over tracking tools; unstable internet connection; electric power interruptions; environmental distractions; and unknown accessibility issues.

One problem is the incompatibility of the browser used in online assessment. It is known that, in the context of business, cross-browser compatibility testing is essential as technology is constantly developing [18]. Thus, translating the context to the online assessment of students, it can be contended that browser compatibility testing enables students to ensure that undesired experiences can be prevented [19]. Though browsers like Google Chrome and Mozilla Firefox dominate the market, people are using their older versions, which typically do not work well with most online proctored test applications.

Another problem is the anxiety over tracking tools during the online assessment. Aside from some incorrect reports generated by tracking tools of online test applications, some students resist for the reason that it may be too invasive. Other students feel bothered and intimidated by the sense that they are being snooped on [20]. A piece of news recently reported testing systems has made some students scared to click too much or rest their eyes for fear that they will be branded as cheats. Other students also said they have cried with pressure or urinated at their desks because they were prohibited from leaving their spots [21].

Furthermore, unstable internet connection has been a constantly reported problem in online assessment. It has been a perennial problem in developing countries like in the context of this study where telecommunication systems are not well developed [22] With the rise of remote learning as an educational necessity that requires an internet connection to different extents, it causes a problem to implement the online assessment. Among the various problems, this situation reveals profound digital divides for many students who do not have the necessary internet services [23] to be able to participate in the online assessment.

The issue of electric power interruptions is another problem in the online assessment. The weather condition is typically the reason why students face sudden power outages [24] while they engage in remote learning, or this case, online assessment. What complicates the situation further is the problem of no electricity at all. A review [25] of reports found out that the statistics of Philippine households without electricity is around 2,319,660 and 2,399,108 with Mindanao as having the most.

Moreover, students have problems in terms of distractions in the environment while taking the online assessment. Whether the noise comes from nature or neighbor, it is argued that remote learning makes it hard to focus because of distractions in the environment. "There are 
sights, smells, and sounds that are part of daily living at home that make it especially hard to focus," as explained [26]. When considering these distractions in online proctored tests, this is a serious problem. While the teacher can review these distractions as not related to dishonesty, it remains a distraction that will affect the concentration of the students.

Lastly, there were also unknown inaccessibility problems that some students encountered. The rush in the need for online proctored test applications has been significant since educational institutions have migrated to the new reality of remote learning [27]. Amid quandary as to what tool can best implement the online test, it is said that there is no perfect solution [28] or testing method [29]. Each online assessment tool has its weakness in its features. Within the case of this study, this weakness is inaccessibility problems that may be unknown and beyond the control of the users.

This article descriptively presented the problems encountered by the students in the online assessment in the context of emergency remote learning. Some of the problems arise from structural conditions unstable internet connection, electric power interruptions, and environmental distractions. Other problems are caused by technical aspects such as incompatibility of browser; anxiety over tracking tools; and unknown accessibility issues. These points are significant in further gaining insights about the hindering factors in the online assessment conducted amid the present global crisis.

\section{Conclusion}

Addressing the practical concerns in online assessment in the current global crisis and the scarcity of knowledge in this area of interest, the present situation offers an opportunity to capture problems in online assessment by exploring the experiences of the students at the present moment. Through a case study, this paper described the problems encountered by college students in online assessment amid the COVID-19 crisis.

The result revealed six themes of problems encountered by the college students in online assessment amid the COVID-19 crisis. These themes are incompatibility of browser; anxiety over tracking tools; unstable internet connection; electric power interruptions; environmental distractions; and unknown accessibility issues. These themes present points of interest that should be provided attention in the continuous improvement of assessment practice and amid the scarce knowledge in this area of interest.

It should be noted, however, that this study is set in a single case, thus the applicability of the results is restricted within the context of the study. There is a need to investigate the same area of interest in other contexts as variations in the sample and environment are expected. This study was also carried out as purely qualitative research. While the results uncovered are valid to some participants, it cannot be ascertained the same to others. Quantitative research may be conducted to determine the extent to which these problems were experienced.

This paper offers useful recommendations for educators. It is suggested that the selection of the application to manage the online proctored test should consider the level of complexity of the application but still maintain the very features that guard the integrity of the assessment. Moreover, given the knowledge about the selected application, it is advised that teachers should prepare plans of possible alternate measures in case inevitable problems occur. Lastly, it is proposed that courses should include an orientation to the test and a test manual should be provided to keep the students guided throughout the assessment process. There is no single best assessment tool for all situations; problems are inevitable. The key is to be proactive.

\section{References}


[1] C. Hodges, S. Moore, B. Lockee, T. Trust, and A. Bond, "The difference between emergency remote teaching and online learning," EDUCAUSE Review, (2020). Retrieved from https://er.educause.edu/articles/2020/3/thedifference-between-emergency-remote-teaching-and-online-learning

[2] Global Education Monitoring Report, "Could coronavirus shape the way assessments work forever?" Author, (2020). Retrieved from https://gemreportunesco.wordpress.com/2020/03/20/could-coronavirus-shape-theway-assessments-work-forever/

[3] M. Townsley, "Grading principles in pandemic-era learning: Recommendations and implications for secondary school leaders," Journal of School Administration Research and Development, vol.5, no.1, pp.8-14, (2020). Retrieved from https://www.ojed.org/index.php/JSARD/article/view/2760

[4] M. B. Cahapay, "Reshaping assessment practices in a Philippine teacher education institution during the coronavirus disease 2019 Crisis,” Pedagogical Research, vol.5, no.4, pp.1-7, (2020). DOI: 10.29333/pr/8535

[5] Commission on Higher Education. Memoranda about COVID-19, (2020). Retrieved from https://ched.gov.ph/blog/2020/03/12/guidelines-for-the-prevention-control-and-mitigation-of-the-spread-ofthe-2019-novel-coronavirus-acute-respiratory-disease-in-higher-education institutions/

[6] E. E. Rotas, and M. B. Cahapay, "Difficulties in remote learning: Voices of Philippine university students in the wake of COVID-19 crisis," Asian Journal of Distance Education, vol.15, no.2, pp.147-158, (2020). DOI: 10.5281/zenodo.4299835

[7] K. V. Middleton, "The longer-term impact of COVID-19 on K-12 student learning and assessment," Educational Measurement: Issues and Practice, vol.39, no.3, pp.41-44, (2020). DOI: 10.1111/emip.12368

[8] T. Gonzalez, M. A. de la Rubia, K. P. Hincz, M. Comas-Lopez, L. Subirats, and S. Fort, "Influence of COVID19 confinement on students' performance in higher education," PLoS ONE vol.15, no.10, pp.e0239490, (2020). DOI: 10.1371/journal.pone.0239490

[9] A. Elzainy, A. El Sadik, and W. Al Abdulmonem, "Experience of e-learning and online assessment during the COVID-19 pandemic at the college of medicine, Qassim university," Journal of Taibah University Medical Sciences, vol.15, no.6, pp.456-462, (2020). DOI: 10.1016/j.jtumed.2020.09.005

[10] K. A. A. Gamage, E. K. de Silva, and N. Gunawardhana, "Online delivery and assessment during COVID-19: Safeguarding academic integrity," Education Sciences, vol.10, no.11, p.301, (2020). DOI: 10.3390/educsci10110301

[11] F. M. Guangul, A. H. Suhail, M. I. Khalit, and B. A. Khidhir, "Challenges of remote assessment in higher education in the context of COVID-19: A case study of Middle East college," Educational Assessment, Evaluation and Accountability, (2020). DOI: 10.1007/s11092-020-09340-w

[12] J. W. Creswell, "Qualitative inquiry and research design: Choosing among five approaches," Thousand Oaks, California, Sage, pp. 191-215, (2013)

[13] V. Braun, and V. Clarke, "Using thematic analysis in psychology," Qualitative Research in Psychology, no.3, pp.77-101, (2006). DOI: 10.1191/1478088706qp063oa

[14] J. W. Creswell, and J. D. Creswell, "Research design: Qualitative, quantitative, and mixed approaches," Los Angeles: Sage, pp.203-216, (2018)

[15] E. Rotas, and M. Cahapay, "From stress to success: Exploring how Filipino students cope with remote learning amid COVID-19 pandemic," Journal of Pedagogical Sociology and Psychology, vol.3, no.1, pp.27-35, (2021). DOI: 10.33902/JPSP.2021366608

[16] E. J. Morris, “Academic integrity matters: Five considerations for addressing contract cheating," International Journal for Educational Integrity, vol.14, no.15, pp.1-12, (2018). https://doi.org/10.1007/s40979-018-0038-5

[17] G. Cluskey, C. Ehlen, and M. Raiborn, "Thwarting online exam cheating without proctor supervision,” Journal of Academic and Business Ethics, vol.4, pp.1-7, (2011)

[18] A. Pai, "Cross browser compatibility testing beyond chrome and firefox," BrowserStack, (2019). Retrieved from https://www.browserstack.com/guide/cross-browser-compatibility-testing-beyond-chrome

[19] R. Jangu, "Guide to browser compatibility for online learning platforms," LambdaTest, (2018). Retrieved from https://www.lambdatest.com/blog/guide-to-browser-compatibility-for-online-learning-platforms/ 
[20] N. Daniels, "Should students be monitored when taking online tests?" The New York Times, (2020). Retrieved from https://www.nytimes.com/2020/05/12/learning/should-students-be-monitored-when-taking-onlinetests.html

[21] D. Harwell, "Cheating-detection companies made millions during the pandemic. Now students are fighting back," The Washington Post, (2020). Retrieved from https://www.washingtonpost.com/technology/2020/11/12/test-monitoring-student-revolt/

[22] E. Aboagye, J. A. Yawson, and K. N. Appiah, "COVID-19 and e-learning: The challenges of students in tertiary institutions," Social Education Research, vol.1, no.1, pp.109-115, (2020). DOI: 10.37256/ser.122020422

[23] A. Tomer, and L. Fishbane, "Bridging the digital divide through digital equity offices," Brookings, (2020). Retrieved from https://www.brookings.edu/research/bridging-the-digital-divide-through-digital-equityoffices/

[24] J. Malasig, "Poor signal and power outage: \#WalangPasok gets new meaning amid distance learning," Interaksyon, (2020). Retrieved from https://interaksyon.philstar.com/trendsspotlights/2020/09/15/176846/poor-signals-and-power-outage-walangpasok-gets-new-meaning-amiddistance-learning/

[25] M. B. Cahapay, "Philippine basic education learning continuity plan: Creating space for indigenous peoples toward inclusive post-COVID-19 education," International Journal of Pedagogical Development and Lifelong Learning, vol.2, no.1, pp.ep 2102, (2021). DOI: 10.30935/ijpdll/9294

[26] B. Cunningham, "8 ways distance learning makes it harder to focus," Understood, (2020). Retrieved from https://www.understood.org/en/school-learning/learning-at-home/homework-study-skills/distance-learningfocus-challenges

[27] S. Jose, "Online proctoring is trending: Here is all you must know," Think Exam, (2020). Retrieved from https://blog.talview.com/a-complete-guide-to-online-remote-proctoring

[28] R. Chase, "How proctorU and examity make cheating on college exams easier than ever," rchase.com, (2018). Retrieved from https://blog.rchase.com/how-proctoru-and-examity-make-cheating-on-college-exams-easierthan-ever/.

[29] J. Dimeo, "Online exam proctoring catches cheaters, raises concerns," Inside Higher Ed, (2020). Retrieved from https://www.insidehighered.com/digital-learning/article/2017/05/10/online-exam-proctoring-catchescheaters-raises-concerns

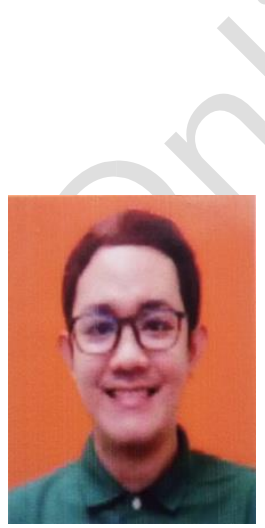

\section{Author}

\section{Michael B. Cahapay}

Michael B. Cahapay is a licensed professional teacher and Assistant Professor at the College of Education, Mindanao State University, General Santos City, Philippines. He is currently completing his Ph.D. in Education major in Curriculum Studies at the University of the Philippines, Diliman. 